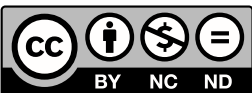

Estudos Teológicos foi licenciado com uma Licença Creative Commons Atribuição - NãoComercial - SemDerivados 3.0 Não Adaptada

http://dx.doi.org/10.22351/etv59i2.3534

\title{
AnotaÇões sobre a Água da VIDa no Apocalipse: MENSAGEM DE VIDA EM UM MUNDO DE MORTE ${ }^{1}$
}

\author{
Notes on the water of life in the book of Revelation: \\ message of life in a world of death
}

Cesar Motta Rios ${ }^{2}$

Resumo: Apresento um estudo da expressão "água da vida” no Apocalipse. Analiso cada uma das quatro ocorrências do sintagma, organizando-as em dois pares. De um lado, duas ocorrências que colocam a doação/recepção da água da vida como algo a se realizar no devir escatológico. De outro lado, duas ocorrências que inserem essa doação/recepção no âmbito presente da comunidade leitora/ouvinte do Apocalipse. O estudo tem aspecto comparativo, levando em conta as ocorrências de expressão semelhante no Evangelho segundo João, a saber, "água viva". A conclusão indica que "água da vida" no Apocalipse tem um duplo aspecto. A imagem é utilizada para se assegurar a realidade de uma vida além da morte, que tanto espreita os primeiros receptores do texto. E é também utilizada como forma de se referir a uma doação já em realização, que torna possível a esperança daquela outra, no futuro.

Palavras-chave: Água da Vida. Apocalipse. João. Escatologia.

Abstract: I offer a study of the expression "water of life" in the book of Revelation. I analyze each of the four occurrences of the syntagma, organizing them into two pairs. On one hand, two occurrences that place the donation/reception of the water of life as something to be accomplished in the eschatological future. On the other hand, two occurrences that insert this donation/reception in the ambit of the present community which read/listen to the Revelation. This study has a comparative aspect, taking into account the occurrences of a similar expression in the Gospel according to John, namely "living water". The conclusion indicates that "water of life" in Revelation has a double aspect. The image is utilized to assure the reality of a life beyond the power of death, which continuously lurks the first receivers of the text. And it is also utilized as a way of referring to the donation already in progress, which makes possible the hope for that other donation, in the future.

Keywords: Water of Life. Revelation. John. Eschatology.

1 O artigo foi recebido em 11 de dezembro de 2018 e aprovado em 12 de março de 2019 com base nas avaliações dos pareceristas ad hoc.

2 Doutor. São Leopoldo, RS. E-mail: cesarmottarios@gmail.com 


\author{
se quer mesmo que lhe diga \\ é difícil defender, \\ só com palavras, a vida, \\ ainda mais quando ela é \\ esta que vê, Severina \\ mas se responder não pude \\ à pergunta que fazia, \\ ela, a vida, a respondeu \\ com sua presença viva. \\ Morte e Vida Severina, \\ João Cabral de Mello Neto
}

\title{
Introdução
}

A expressão "água da vida" é facilmente tratada como intercambiável com a muito semelhante "água viva". Ambas ocorrem no Novo Testamento, somente no Apocalipse e no Evangelho segundo João, respectivamente. Ambas são passíveis de

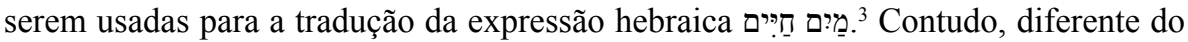
que acontece com o par "pão vivo" / "pão da vida", que ocorre paralelamente no capítulo 6 do Evangelho joanino 4 , "água viva" ocorre somente no evangelho ${ }^{5}$, enquanto "água da vida" ocorre somente no Apocalipse.

Será inevitável uma consideração comparativa dos dois documentos. Ainda assim, ressalto que este estudo procura contribuir especificamente para o entendimento do valor e da dinâmica da expressão "água da vida" no Apocalipse. Inicialmente, tecerei breve comentário sobre as ocorrências da expressão, que são quatro, organizadas em dois grupos: de um lado, aquelas que parecem apresentar uma visão da realidade instaurada no devir pela ação divina; de outro, aquelas que parecem apresentar um convite (uma exortação) ao ouvinte/leitor do texto, explícito ou não, na cena da escrita ou na cena da leitura litúrgica. Em seguida, desenvolvo uma breve reflexão sobre a dinâmica da expressão no livro, considerando-a, 1) por um lado, como parte de uma rede maior de expressões que tem por objetivo comunicar de modo enfático a doação da vida eterna e, por contraste, a supressão da morte, e, 2) por outro lado, como elemento de uma escatologia já em realização na vida presente da comunidade de fé.

Entendo que a realidade histórico-social vivenciada pelas primeiras pessoas leitoras/ouvintes do Apocalipse pode ser descrita como mundo de morte. Trata-se de um contexto de pobreza para a maior parte da população, que vive sem reservas de

3 Cf., na Bíblia Grega, Jr 2.13, que utiliza construção com genitivo ("água da vida”) e, entre numerosas ocorrências semelhantes, por exemplo, Nm 19.17, que recorre à construção com particípio presente ("água viva/vivente").

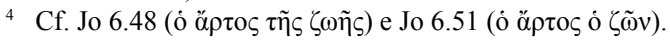

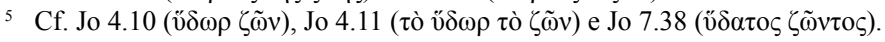


riquezas, lutando diariamente pela subsistência. ${ }^{6}$ Além disso, as pessoas que compunham as comunidades de fé nas quais se lia o Apocalipse experimentavam o agravamento dessa situação por hostilidades de outras partes da população ${ }^{7}$ e obstáculos para a sua inserção nas relações econômicas fundamentais. ${ }^{8}$ A morte se mostrava presente nas dificuldades cotidianas, nas incertezas da vida e na agressividade de pessoas que compartilhavam as mesmas cidades, as mesmas ruas com os seguidores do nazareno crucificado, o Cordeiro da narrativa apocalíptica de João. Em uma situação assim, torna-se especialmente significativa e urgente a comunicação pretendida pela expressão "água da vida", como procurarei demonstrar.

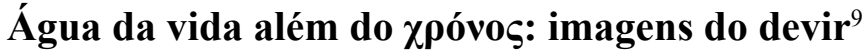

A primeira ocorrência da expressão no livro se dá em um trecho localizado entre a abertura do sexto selo e a abertura do sétimo. Os acontecimentos que João vê ao se abrir o sexto selo são devastadores. As pessoas se veem em desespero. Há certa ênfase para a participação dos ricos e poderosos como aqueles que padecem (Ap. 6.15). ${ }^{10}$ Fogem, mas a fuga não basta. Agora, para eles, a morte reina sobre a vida. Antes do sétimo selo ser aberto, há uma nova visão, iniciada em Apocalipse 7.2. Estávamos diante do iminente desfecho, da grande peripécia coletiva dos grandes da terra. Então, subitamente, somos levados a uma cena celeste. Haveriam de ser selados 144 mil pessoas, 12 mil de cada uma das 12 tribos de Israel. João escuta esses números. Olha e vê uma multidão composta por gente de todos os povos. Em seguida, um diálogo entre João e um ancião revela que esses são santos vindos da grande tribulação.

6 Cf. FRIESEN, Steven. Poverty in Pauline Studies: Beyond the So-called New Consensus. JSNT, v. 26, n. 3, p. 323-361, 2004.

7 FRIEDRICH, Nestor. Adapt or Resist? A Socio-Political Reading of Revelation 2.18-29, JSNT, v. 25, n. 2, p. 185-211, 2002. p. 195-198.

8 KRAYBILL, J. Nelson. Imperial Cult and Commerce in John's Apocalypse. Sheffield: Sheffield Academic Press, 1996. p. 29.

9 O referencial que sigo para a construção deste tópico e do seguinte a partir das categorias khrónos e kairós está em um texto de Élian Cuvillier, cujo teor se explicita suficientemente no seguinte trecho: "João procede, assim, a uma requalificação do presente: contra uma possível compreensão da apocalíptica, não se trata de fugir para fora do mundo numa espera pelo futuro (se permanece, então, no khrónos) e contra o entusiasmo (negação do khrónos por um kairós desencarnado): o presente da fé (essa que Paulo

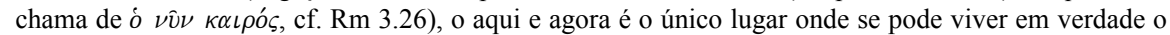
Evangelho" (CUVILLIER, Élian. La construction de la temporalité et de l'espace dans quelques textes de l'Apocalypse de Jean. Implications theologiques, anthropologiques et politiques. Conférence donnée dans le cadre du symposium du RRENAB («Narrativité et politique», 2-4 juin 2017, Université Laval à Québec). Disponível em: <www.academia.edu/35829016/LA_CONSTRUCTION_DE_LA_TEMPORALITE_ET_ DE LESPACE DANS QUELQUES TEXTES DE LAPOCALYPSE DE JEAN. IMPLICATIONS THEOLOGIQUES_ANTHROPOLOGIQUES_ET_POLITIQUES_1>. Acesso em: 14 jun. 2018.p. 4).

${ }^{10}$ A ênfase se dá não por exclusão daqueles que não são ricos, mas pela menção mais detalhada daquelas classes de pessoas ordinariamente dotadas de recursos materiais e poder. Essa observação mais atenta para o destino desses poderosos pode residir no fato de que os que já viviam em posições mais subservientes e precárias vivenciam um agravamento de sua situação, mas não uma novidade completa. Poder-se-ia dizer que se trata de uma questão de noticiabilidade. 
Servem a Deus diante do trono. Além dessa descrição do que ocorre diante dos olhos do vidente, alguma informação é oferecida sobre o que haveria de acontecer a eles:

Já não passarão fome, nem terão sede. Já não cairá sobre eles o sol, nem todo calor.

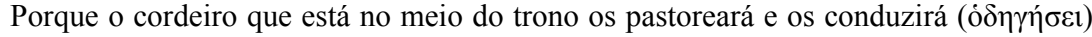

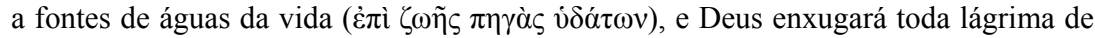
seus olhos (Ap 7.16-17).

Os verbos no futuro indicam que o que se narra está fora do âmbito da cena vista, estando reservado para o devir. O versículo 17, que nos interessa diretamente, traz óbvias alusões ao Antigo Testamento. Por exemplo, a figura do pastoreio nos remete facilmente a Ezequiel (34.12ss), que, possivelmente, já aparece trabalhado em João (10.11ss), ou ao Salmo 23. Notável, aqui, é o fato de que não só Jesus aparece como o pastor, mas aparece apresentado como um Cordeiro-pastor. O estranhamento inevitável se deve ao fato de que cordeiros são, no âmbito literal, pastoreados, não pastores. Do nome $\mathrm{YHWH}^{11}$, passamos ao Cordeiro, que é Jesus ressurreto, pastor identificado com a natureza dos pastoreados. ${ }^{12}$ Essas conexões deixam claro que a promessa para o devir não é fruto de uma capacidade imaginativa à deriva, mas que se enraíza nas Escrituras. Não obstante, se essa relação intertextual com o cânone da Bíblia Hebraica produz certa segurança no leitor, fornecendo-lhe uma ancoragem específica, outra relação possível com o quarto evangelho pode ser perturbadora para um leitor detalhista.

Primeiramente, há uma dificuldade espacial. Esses que alvejaram suas vestes

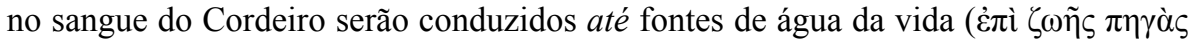
v́dó $\tau \omega v$ - Ap 7.17) ${ }^{13}$. No evangelho, a fonte da água viva surge dentro da pessoa

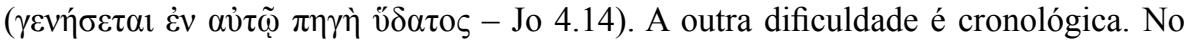
evangelho, a "água viva" parece ser algo necessário para que a pessoa exista como parte do povo de Jesus. ${ }^{14}$ Ela figura como parte de uma escatologia em realização, e

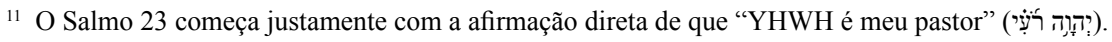

12 "Em Cristo, o Pastor tomou a natureza das ovelhas" (SWETE, H. B. Commentary on Revelation. Grand Rapids: Kregel, 1977. p. 105). Mounce entende que o paradoxo perde força se considerarmos o Cordeiro no Apocalipse como trazendo a ideia da liderança messiânica (MOUNCE, Robert. The Book of Revelation. Grand Rapids: Eerdmans, 1977. (The New International Commentary on the New Testament). p. 175. É, ademais, possível que o termo Cordeiro tenha ocorrido aqui, como sujeito da ação de pastorear, simplesmente pela recuperação do último termo utilizado para Cristo (cf. Ap 7.14). Ainda assim, é certo que um leitor/ ouvinte cristão atento, em qualquer época, poderia associar a "escolha" lexical ao tema da encarnação.

${ }^{13}$ Swete me parece correto ao observar que a anteposição do genitivo $\zeta \omega \tilde{s}$ pretende ênfase (SWETE, 1977, p. 105). A primeira ocorrência de "água da vida" no Apocalipse destaca o valor Vida, o que me parece coerente com o que entendo ser objetivado com a imagem e outras semelhantes.

${ }^{14}$ Isso vale tanto para o caso de se interpretar a "água da vida" do quarto evangelho como sendo o Espírito Santo, quanto para o caso de se entender que se trata de ensino/Palavra. Há um possível paralelo instigante em 1 Enoque 48.1. O visionário relata a visão de uma fonte de justiça rodeada por muitas fontes de sabedoria. Os sedentos bebiam delas e eram satisfeitos com sabedoria. Loren Stuckenbruck e Mark Mathews entendem que esse texto enóquico estaria mais próximo de João 4 que da afirmação do Apocalipse (STUCKENBRUCK, Loren; MATHEWS, Mark. The Apocalypse of John, 1 Enoch, and the Question of Influence. In: FREY, Jörg, KELHOFFER, James; TÓTH, Franz. (Eds.). Die Johannesapokalypse: Kontexte 
não como algo que a pessoa deva esperar para um outro tempo, como uma escatologia ainda em expectação.

De fato, não há como desconsiderar que a construção desses versos de Apocalipse aponta para um tempo diferente. Trata-se, justamente, de uma antecipação (no texto) da imagem que se revelará no capítulo 22 .

Em Apocalipse 22.1, encontramos "um rio de água da vida" saindo do trono de Deus e do Cordeiro. A imagem, que é mostrada a João em contiguidade com a exposição da nova Jerusalém, tem conexões complexas com o Antigo Testamento. Gênesis 2-3, Zacarias 14 e Ezequiel 47 parecem contribuir com elementos, sendo esse último texto o mais importante na construção. ${ }^{15}$ Águas que saem do Templo e águas que permeiam o paraíso se encontram aqui. Não é estranho que Éden e Templo se entrelacem na imagem apocalíptica que, no presente caso, prenuncia o devir, inclusive porque, também olhando para o passado narrado no Gênesis, algum escritor judeu, responsável pelo livro de Jubileus, podia ver no Éden atributos do Templo. ${ }^{16}$ Há um novo Templo na Nova Jerusalém, mas não feito de pedras. Trata-se da presença do próprio Deus e do Cordeiro. Eles são o Templo (Ap 21.22). O Templo já não é espaço de mediação da presença, mas a presença em si. É desse Templo, do trono de Deus e do Cordeiro, que flui o rio. O Apocalipse parece propor que Ezequiel seria preciso, mas que não deveria ser entendido como indicando uma realidade histórica desenrolada na Jerusalém terrena, e sim algo além do plano histórico, além do khrónos.

Contudo, ainda que esse lugar seja excepcional e não exatamente como o Templo de pedras da Jerusalém histórica, em princípio, trata-se de um lugar. Essa água da vida está, pois, num lugar específico, que, por sua vez, se faz acessível num tempo específico, além do tempo.

- Konzepte - Rezeption. Tübingen: Mohr Siebeck, 2012. p. 209). Não obstante, o contexto visionário semelhante me parece suficiente para que se considere uma aproximação com o Apocalipse. Curiosamente, por outro lado, o fato de ser uma fonte de sabedoria, não de água viva/da vida, favorece certo entendimento menos comumente considerado para a "água viva" em João: discurso/ensino da parte do Messias (RIOS, Cesar Motta. "Águas vivas" no Evangelho segundo João, na Bíblia Hebraica e nos manuscritos do Mar Morto: Entre Continuidades e Diferenças. Estudos Teológicos, v. 57, n. 1, p. 157-170, jan./jun. 2017.). A partir de uma leitura comparativa com essa passagem de Enoque, seria possível propor uma aproximação entre as ocorrências da expressão no quarto evangelho (juntamente com outras do Apocalipse, como se verá) e esta. Contudo, considero ainda arriscada uma reflexão fundamentada nessa parte do Livro de Enoque, que é conhecida por Livro das Parábolas ou Livro das Similitudes, uma vez que foi preservada somente em Etíope, em contexto cristão (MARTÍNEZ, Florentino García; TIGCHELAAR, Eibert J. C. (Eds.). The Dead Sea Scrolls Study Edition. Leiden; New York; Köln: Brill, 1999. 2 v. p. 144-145). O que ali se encontra pode ser trazido diretamente de um original judaico anterior ao Apocalipse, mas é também possível, ainda que isso não represente a opinião geral dos especialistas (CHARLESWORTH, J. H. The Old Testament Pseudepigrapha and the New Testament: Prolegomena for the Study of Christian Origins. Cambridge: Cambridge University Press, 1985. p. 89), que reflita influência do próprio texto do Apocalipse.

${ }^{15}$ MACASKILL, Grant. Paradise in the New Testament. In: BOCKMUEHL, M.; STROUMSA, G. G. Paradise in Antiquity. Cambridge: Cambridge University Press, 2010. p. 64-81. p. 76-77.

16 ANDERSON, Gary. The Garden of Eden and sexuality in early Judaism. In: EILBERG-SCHWARTZ, H. People of the body: Jews and Judaism from an embodied perspective. Albany: State University of New York Press, 1992. p. 47-68. p. 54-55. 
Decerto, essa constatação, que torna o lugar da "água da vida" mais determinado, e que mantém uma diferença para com o uso de "água viva" no quarto evangelho, poderia ser desestabilizada por uma leitura diferente do trecho. Robert Gundry propõe que a nova Jerusalém não seja uma cidade, mas um grupo de pessoas. Ainda assim, mantém um contraste entre os santos na presente realidade e essa realidade final. A descrição da cidade traria, em uma imagem de escatologia futurística, certa forma de aguçamento de elementos já considerados numa escatologia realizada presente no evangelho joanino. ${ }^{17}$ Stanley discorda de Gundry e propõe que se entenda a Nova Criação como povo, mas também lugar, caracterizado por meio da promessa de água como tendo uma vida à maneira do Éden antes do pecado. ${ }^{18}$ Ponto importante a se considerar é que, mesmo sendo (também) povo, a Nova Criação é uma nova criação de Deus.

A percepção de que o que se descreve em Apocalipse 21 - 22 não é somente um lugar, mas também pessoas, viabiliza certa continuidade com o uso de "água viva" no evangelho. Discretamente, também aqui temos a água nas pessoas. Permanece, contudo, o problema do afastamento cronológico. Ademais, se essa identificação da Nova Jerusalém com as pessoas é necessária, o destinatário do texto teria que se esforçar para, quando da leitura/escuta desse trecho, retornar ao capítulo 7 e entender de modo bastante atípico a afirmação sobre o que o Cordeiro faria àquelas pessoas.

Parece-me que, de fato, essas duas ocorrências até aqui consideradas tendem a uma concepção diferente da do quarto evangelho, uma vez que a "água da vida" figura nelas como elemento outorgado em um momento escatológico que ainda se espera. Esse elemento assegura a doação da vida, uma vida sustentável, sem fim, saciada. ${ }^{19}$ Sobre o "rio de água da vida", Jacques Ellul afirma com sensatez:

É uma incessante contribuição de vida que é efetuada pelo rio que sai desse trono: é um jorrar da própria vida. Esta vem diretamente (aqui também a mediação é suprimida) de Deus para toda a sua criação e para cada criatura. Há uma corrente contínua de vida: é o símbolo muito claro da relação imediata do "Deus-com-os-homens"20.

Uma observação somente é importante para a reflexão desenvolvida no presente trabalho: essa situação de imediação precisa ser ela mesma, no ato de comunicação estabelecido por esse livro da profecia, mediada pela imagem de um elemento material reconhecível e apreciado positivamente por parte do leitor e dos ouvintes: a água em movimento, água de boa qualidade.

${ }^{17}$ GUNDRY, Robert. The New Jerusalem - People as Place, Not Place for People. Novum Testamentum, XXIX, 3, p. 254-264, 1987. p. 262.

18 STANLEY, John E. The New Creation as a People and City in Revelation 21:1-22:5: An Alternative to Despair. The Asbury Theological Journal, v. 60, n. 2, p. 25-38, 2005. p. 30.

19 Alguém poderia objetar que essas ocorrências de "água da vida" deveriam ser lidas como tendo um sentido simplesmente literal, de "água corrente/boa”, não havendo sentido mais profundo a se procurar. Parece-me, contudo, que a própria natureza do Apocalipse como um todo torna pouco plausível essa possibilidade.

${ }^{20}$ ELLUL, Jacques. Apocalipse: Arquitetura em movimento. Trad. Maria Luísa de Albuquerque Silva. São Paulo: Paulinas, 1979. p. 255. 


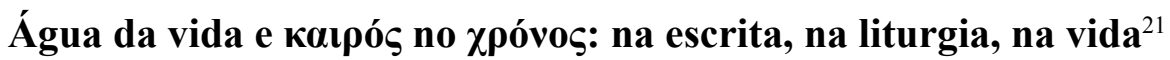

O capítulo 21 do Apocalipse apresenta o novo Céu e a nova Terra. Não há novo mar. "O mar já não existe” (Ap 21.1). O mar é água em sua forma mais ameaçadora. Navegar é expor-se à morte. Não é surpreendente que a última frase no trecho, antes que uma fala interrompa o fluxo da descrição/narração, comece anunciando: "A morte não existirá mais" (Ap 21.4)..$^{22}$

Então, essa cena que nega o mar e a morte introduz a fala daquele que está assentado no trono:

E disse o que está assentado no trono: Eis que faço novas todas as coisas. E diz: Escreve, porque estas palavras são fieis e verdadeiras. E disse-me: Está feito. Eu sou o alfa e

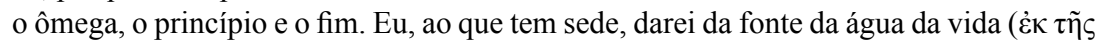

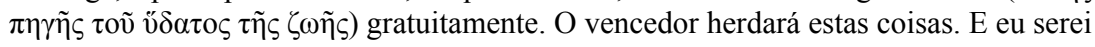
para ele Deus, e ele será para mim filho. Mas para os covardes, infiéis, abomináveis, assassinos, sexualmente imorais, feiticeiros e idólatras e todos os mentirosos, a parte deles é o lago que queima com fogo e enxofre, que é a segunda morte (Ap 21.5-8).

O verbo no futuro parece manter a "água da vida" ainda distante do ouvinte. Não obstante, proponho que a construção como um todo promove uma maior aproximação com o contexto do leitor/ouvinte, por relacionar a promessa com a escrita do livro que é lido. ${ }^{23}$ Aquele que faz tudo novo ordena a escrita, que se justifica pelo caráter

21 Julgo conveniente, para fins de esclarecimento, começar também este tópico com uma citação que revela algo que tenho por referência: "A temporalidade implementada pelo Apocalipse na abertura de seu livro se caracteriza por uma proximidade que é o inverso de uma precipitação. Ela não é comandada pela pressão de um khrónos, mas pela proximidade do kairós que se inscreve sem precipitação e, se poderia quase dizer, sem urgência, no desenrolar do khrónos. É a "leitura/escuta" de uma "profecia" que interroga o mundo" (CUVILLIER, 2017, p. 4).

22 A exclusão do mar na nova criação parece ter a exclusão da morte como paralelo importante. Charles encontra paralelos notáveis no Testamento de Levi (4.1), em Assunção de Moisés (10.6) e nos Oráculos Sibilinos $(5.159,160,446$ e 8.236). Observando esses trechos mais detidamente, percebo que não tratam de uma inexistência do mar, mas da extinção das águas em geral. Em seguida, o comentarista sugere que essa passagem não aponta para um "horror semítico do mar", mas que diz respeito a conexões com o mito babilônico da criação. Não obstante, termina o comentário desse trecho citando como paralelo a se destacar Sobre Isis e Osírides (7) de Plutarco, que, justamente, apresenta um entendimento do mar "como um elemento estranho na natureza, repleto de destruição e doença" (CHARLES, R. H. A Critical and Exegetical Commentary on The Revelation of St. John. Edinburgh: T \& T Clark, 1920. (The International Critical Commentary). v. II, p. 205. Parece-me que a supressão do mar indica que o elemento água passa a figurar somente em sua forma benéfica. As referências que Swete provê para demonstrar a negatividade do mar no imaginário antigo corroboram essa leitura (SWETE, 1977, p. 275-276). A abundância da água da (ou "de") vida é acompanhada pela inexistência de água de morte. Isso não significa que a imagem do mar seria perfeito e exclusivo oposto da "água da vida" no Apocalipse. É, isso sim, um dos elementos de contraste. Convém considerar também, por exemplo, o vômito do dragão (Ap 12.15-17; cf. LAZARIN, Cleide. A água da vida e o sentido da vida. 2013. Dissertação (Mestrado em Ciências da Religião) Pontifícia Universidade Católica de Goiás, Goiânia, 2013. p. 208-209).

23 Swete também contrasta Ap 7.17 com o trecho agora em análise por entender que, enquanto, naquele versículo, se antecipa o "estado perfeito", neste último (assim como em Ap 22.17, que também estudarei 
verdadeiro dessa palavra. Uma questão surge: de que palavras se diz isso? João havia visto uma cena ( $\varepsilon \tilde{i} \delta o v$ ) e não lido um relato. Seriam as palavras que ainda haveriam de ser escritas? As palavras que estão na mente do vidente (que já comera um livro)? Em seguida, imediatamente antes da frase que me interessa, aquele que está assentado no trono ressalta sua identidade nos seguintes termos: "eu [sou] o alfa e o ômega, o

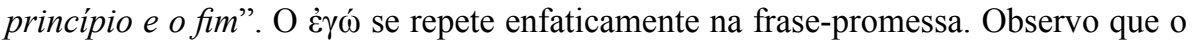
tema da escrita, iniciado com o imperativo em 21.5, ecoa na identidade do falante que

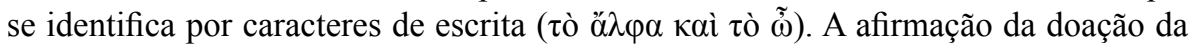
água da vida está, então, mediada pela escrita, que não é meio estranho, mas escolhido e adequado. Sugiro que a escrita da promessa torna presente de modo antecipatório aquilo que nela está prometido. Quero dizer, a cena de escrita (processo) atrelada, no texto mesmo, à promessa da água faz com que a própria escrita (produto) traga em si certa potência do prometido.

A última cena em que aparece a "água da vida" no Apocalipse parece complementar essa associação com a escrita. Em Apocalipse 22.6-21, encontramos o desfecho do livro em forma dialogal. De início, o diálogo acontece somente com João e diz respeito, novamente, à escrita do livro e seu uso (cf. Ap 22.6-7,9-10,13). A identidade

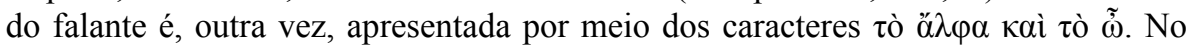
versículo 16, enfatiza-se o emissor último da profecia e os destinatários. Então, os ouvintes, que pareciam já implicados em 22.9, são inseridos na cena: "E o Espírito e a noiva dizem: Vem! E aquele que ouve diga: Vem! E aquele que tem sede venha, aquele que quer receba água da vida gratuitamente" (Ap 22.17). O público ouvinte interage com o leitor, respondendo verbalmente nesse ponto da leitura. Após essa fala de quem escutou em silêncio durante muito tempo, figura não mais uma promessa futura sobre a água da vida, mas um convite presente. É na cena litúrgica da leitura comunitária que se estabelece o oferecimento efetivo da água. Aqui, pois, se realiza o que me parecia sugerido discretamente na cena de escrita de Ap 21.5-8: a "água da vida" está disponível no evento da leitura do livro escrito por João. Nesse caso, o elemento que aparecia somente como imagem de uma escatologia esperada, aquela da nova criação, é, agora, trazido como elemento de uma escatologia em realização (e em performatização).

neste tópico), "é para a Igreja e mundo na sua condição presente que a água da vida é prometida" (SWETE, 1977, p. 280). Brighton, diferentemente, comentando Ap 21.6, embora reconheça a relação com João 7.37 e João 4.10-14, não nota a necessidade, revelada por essa relação, de que se trate de algo já vivido pela igreja: "Agora, na conclusão da mensagem profética do Apocalipse e em referência a todas as coisas feitas novas, Deus lembra João desse convite [antes, o autor mencionara Isaías 55.1 e os trechos do Evangelho de João referidos], um convite que João e o povo de Deus consideraram atentamente, e cuja fruição eles veem agora no novo céu e terra" (BRIGHTON, Louis A. Revelation. Saint Louis: CPH, 1999. (Concordia Commentary). p. 603). Koester, a meu ver sem devidos argumentos e, provavelmente, sem considerar a possibilidade de variação no âmbito do próprio Apocalipse, entende que é mais adequado distinguir a água que se tem no evangelho (que seria para o presente) e a que se tem no Apocalipse em geral, que se relaciona com a ressurreição que ainda está por acontecer (KOESTER, Craig R. Revelation - A New Translation with Introduction and Commentary (The Anchor Bible). New Haven; London: Yale University Press, 2014. p. 423). 
O que segue do texto é uma ameaça que reafirma a confiabilidade do que se escutou (Ap 22.18-19), e uma repetição enfática do pequeno diálogo envolvendo os

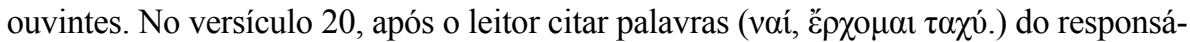
vel último pelo testemunhado no livro lido, eles novamente responderiam em voz alta: “Amém! Vem, Senhor Jesus". O versículo 21 encerra a reunião de leitura litúrgica de forma breve, mas suficiente para indicar que o evento transcende o seu tempo de realização. A graça do Senhor Jesus acompanhará cada ouvinte em sua vivência cotidiana.

Então, se bem observado o texto, o convite para o recebimento da "água da vida" está após toda e qualquer promessa dada à audiência (com uso de verbos no futuro). $\mathrm{O}$ que vem depois é, repito para enfatizar, um alerta que garante a fidedignidade do que foi lido (que atesta a qualidade da água oferecida na reunião), uma repetição litúrgica do diálogo com os ouvintes e o encerramento da reunião. A “água da vida” tem, assim, um destaque considerável como aquilo que não só está prometido para o futuro, mas também que se oferece com o processo mesmo de leitura do livro, o que se explicita nesse término. Correndo risco de ser redundante, exponho a organização que proponho para o texto de Ap 22.10-21, citando-o e acrescentando comentários pontuais:

Leitor: E me diz: Não seles as palavras da profecia deste livro, pois o momento oportuno (ó אaıpòs) está próximo. [A leitura do livro é conclamada por Jesus e tem relação com o kairós].

Aquele que pratica injustiça pratique-a ainda. $\mathrm{O}$ imundo ainda se torne imundo. $\mathrm{O}$ justo pratique ainda a justiça. E o santo ainda seja santificado.

Eis que venho depressa, e o meu salário vem comigo para retribuir a cada um conforme é a sua obra. [Até aqui, a fala acentua o fato de serem tempos escatológicos os vividos pela comunidade.]

Eu sou o alfa e o ômega, o primeiro e o último, o princípio e o fim.

Bem-aventurados são os que lavam suas vestes, para que venha a haver para eles a permissão sobre a árvore da vida e entrem pelas portas para dentro da cidade.

De fora, os cães, os feiticeiros, os sexualmente imorais, os assassinos, os idólatras e todos os que amam e praticam mentira. [Nos versículos 14 e 15, o grupo dos ouvintes é dito bem-aventurado e contraposto aos demais.]

$\mathrm{Eu}$, Jesus, enviei meu anjo para testemunhar a vós estas coisas para as igrejas. Eu sou a raiz e a tribo de Davi, a radiante estrela matutina. [Nos versículos 13 e 16, a identidade do responsável último pelas palavras é reafirmada.]

Leitor: E o Espírito e a noiva dizem: Vem! E o ouvinte diga: [O conector kaì parece marcar, aqui, uma mudança no discurso. Na performance da leitura, poder-se-ia indicar também por modulação da voz e gesto a proximidade de um diálogo. $]^{24}$

${ }^{24}$ Suspeito que o trecho iniciado aqui, que segue até o versículo 19, seja do próprio leitor, e não atribuído a Jesus. Nisso, concordo aparentemente com Vanni, que atribui a "João" essa parte do discurso (VANNI, Hugo. Apocalipse: uma assembleia litúrgica interpreta a história. São Paulo: Paulinas, 1984. p. 192). E, para esse estudioso, o leitor personifica João (VANNI, 1984, p. 196). Não obstante, o fato de que Cristo

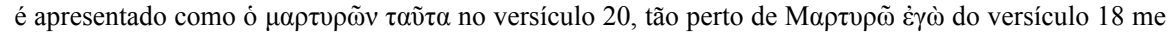
convida à cautela. Embora entenda que o testemunho implicado no v. 20 diga respeito a todo o livro, a repetição lexical produz um vínculo considerável. 
Ouvintes: Vem! ${ }^{25}$

Leitor: E o sedento venha. O que quer receba água da vida gratuitamente.

Eu testemunho a todo que ouve as palavras da profecia deste livro: Caso alguém acrescente sobre elas, acrescentará Deus sobre ele as pragas escritas neste livro. [Há nova mudança no discurso, perceptível no verbo em primeira pessoa, que ocupa o primeiro lugar na frase. Essa mudança poderia ser marcada por uma pausa, de modo que, na leitura, assim como no texto, a frase da oferta da água da vida tivesse destaque como encerramento do trecho dialogal.]

E caso alguém retire das palavras do livro desta profecia, Deus retirará sua parte da

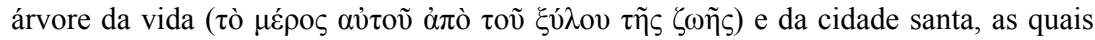
estão escritas neste livro.

Leitor (marcando novo trecho dialogal): Aquele que testemunha estas coisas diz: Sim, venho depressa.

Ouvintes: Amém, vem, Senhor Jesus.

Leitor (Encerrando a leitura pública): A graça do Senhor Jesus esteja com todos.

\section{Considerações finais}

Parece-me necessário reconhecer certa ambivalência da expressão "água da vida" no Apocalipse. Lendo especificamente as ocorrências da expressão nos convites (Ap 22.17 e 21.6), tem-se a impressão de que o sentido pode ser estritamente aquele da expressão "água viva" no evangelho joanino. Por outro lado, as outras ocorrências (Ap 7.17 e 22.1) direcionam o leitor a uma consideração diferente, que associa a "água da vida" a um conjunto de elementos propriamente localizados no devir escatológico. A “água da vida" é, nesse caso, um entre outros elementos que figuram no texto do Apocalipse como imagens ou objetos que confirmam a doação definitiva da vida após a presente era, nomeadamente, a "árvore da vida", a "coroa da vida" e o "livro da vida". ${ }^{26}$

Essa ambivalência ${ }^{27}$, que parece não se resolver de modo pleno, faz com que a expressão tenha, ao mesmo tempo, um valor de continuidade para com o evangelho

25 A percepção desse trecho como dialógico me ocorre a partir do versículo 17 e do trabalho de Hugo Vanni, embora ele atribua à assembleia reunida uma fala maior do que a que me parece mais plausível. Para Vanni, o povo dirá: 'O Espírito e a Esposa dizem: 'Vem!' Que aquele que ouve diga também: 'Vem!' (VANNI, 1984, p. 192). A meu ver, "aquele que ouve” é (em conjunto com cada outra pessoa que ouve) a assembleia em si. Entendo que o leitor lê até o imperativo de terceira pessoa e espera a resposta do ouvinte. Uma diferença mais ampla está no fato de que Vanni divide o discurso entre Cristo, João e a assembleia. Prefiro restringir-me ao leitor e aos ouvintes.

${ }^{26}$ É arriscado e desnecessário (para o discernimento do efeito pretendido pelo texto) propor uma identificação mais específica do que é simbolizado por essa água da vida presente na nova criação. Trata-se de algo providenciado por Deus, viabilizado por Cristo. Indo além disso, alguém pode facilmente se ver enredado entre diferentes opções igualmente plausíveis.

27 Algum incômodo pode surgir a partir dessa proposta que identifica significados diferentes para uma mesma expressão significante que se repete ao longo do texto. Observo que não se trata de dissociação completa entre os significados, nem mesmo de interpretação diversa do genitivo. A diferença da instância em que se usa a expressão produz uma diferença de nuance. É possível até mesmo suspeitar que quem produz o texto pode não dar-se conta de toda a diferenciação passível de ser notada na leitura. A causa dessa 
joanino e um valor definido por sua colocação na rede de sentido construída internamente no Apocalipse. Semelhantemente, além da questão do âmbito textual ao qual se dirige o olhar, está a questão da dimensão temporal ou escatológica implicada em cada uma dessas nuanças implicadas na expressão: escatologia esperada e escatologia em realização se discernem entre as diferentes ocorrências, sendo cada uma enfaticamente colocada em duas delas, mas, significativamente, elas se tocam pelo uso da mesma expressão significante. Ainda que o significado em cada caso seja diferente, essa ambivalência de "água da vida" recupera e ressalta o caráter escatológico do que se desenvolve já no presente pela oferta da "água da vida" (Apocalipse) ou "água viva" (João).

Proponho que há dois conjuntos possíveis, sendo que as ocorrências no Apocalipse que tratam do oferecimen to dessa água à comunidade leitora/ouvinte estariam na fronteira, pertencendo a ambos. O duplo pertencimento dessas ocorrências serviria de elo entre as demais, viabilizando um grande conjunto mais amplo, que expressa uma possível influência mútua (ainda que de difícil explicitação) dos dois conjuntos menores:

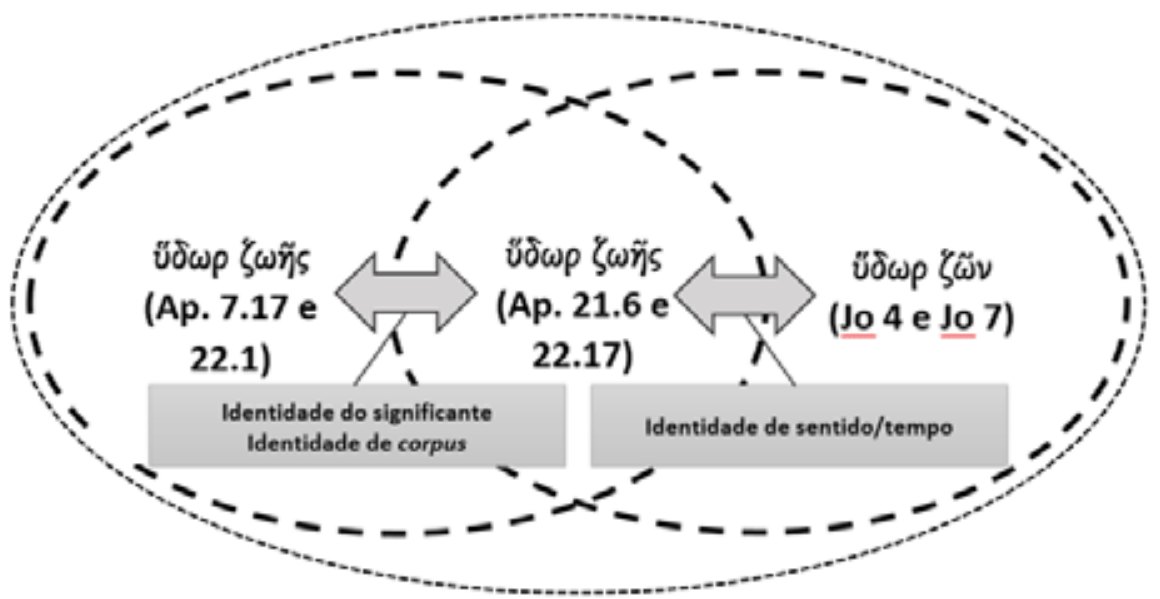

Figura 1 Relação entre expressões do Apocalipse e do Evangelho segundo João

Entendendo que essa comunicação do círculo mais amplo torna evidente o caráter escatológico de toda "água da vida" ou "água viva", seja a do presente, seja a da nova criação, falta-me refletir sobre como a ideia de "vida" participa de cada um dos conjuntos menores, ou melhor, como um conjunto influencia a leitura do outro.

ambivalência pode estar na manifestação de algo bem discernido por Penner nos hodayot dos manuscritos de Qumran: uma justaposição entre presente e futuro escatológico. O pesquisador conclui que a "poesia conecta ações passadas de Deus, as experiências presentes do poeta e o destino futuro do povo de Deus" (PENNER, Ken. Realized or Future Salvation in the Hodayot. Journal of Biblical Studies, v. 2, p. 1-49, 2002. p. 46). Proponho que essa confluência entre temporalidades diferentes - presente e devir - ocorra na concentração das duas dimensões na expressão "água da vida”. 
Em um mundo de hostilidade e precariedade, em que se caminha constantemente à sombra da morte, ou melhor, sem que seja possível esquecer por uns dias dessa sombra e ter descanso, a promessa de vida não fica despercebida, mas precisa ser enfática. A água da vida vista na nova criação é imagem que serve de suporte para o valor que é dado aos fiéis, a vida. Ou seja, a doação da vida por parte de Deus é comunicada por meio de um suporte reconhecível e significativo no khrónos, no mundo/tempo presente. A reflexão de Greimas (1987) no campo da semiótica a respeito dos objetos de valor ajuda a entender a relevância desse procedimento. Em vez de afirmar uma realidade abstrata desprovida de visualidade, narrativas trabalham com a junção ou disjunção de personagens com objetos dotados de valor. Em vez de dizer que alguém ficou rico, um texto pode afirmar que tal pessoa ganhou ou adquiriu um saco de moedas de ouro. Havia disjunção entre personagem e objeto. Passa a haver junção. Nesse momento, o valor "riqueza” lhe é atribuído. A “água da vida" seria um objeto de valor. A narrativa do Apocalipse anunciaria aos fiéis que haveria uma junção deles com esse objeto por meio de uma doação, de modo que entendam e vejam que receberão vida.

Já a "água da vida" (ou “água viva") recebida no presente é elemento vital para a existência dos fiéis enquanto fiéis, constituindo-se como aquilo que torna a pessoa que vive neste tempo de morte participante (em expectativa) também daquela "água da vida" final. Ou seja, sem uma "água da vida" presente, não há esperança da "água da vida" do devir. São elementos específicos, mas um transborda no outro. Um torna a pessoa esperançosa própria para o outro, que é o esperançado. Faz de alguém nova

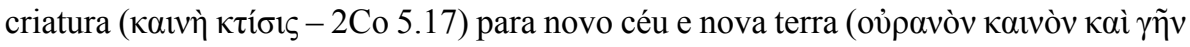
каıvฑ́v-Ap 21.1).

No tempo presente, há uma esperança da água da vida da Nova Terra (do devir escatológico) em cada pessoa que ouve e guarda a Palavra (sobre o Cordeiro) - também chamada água da vida - no contexto de uma vida difícil de se defender, que, sem essa água, pereceria em árida desesperança. Essa dinâmica me parece bem comunicada nas palavras de Inácio de Antioquia: “O meu desejo já está crucificado. E não há em mim um fogo que ama coisas materiais, mas, em mim, há água viva e falante

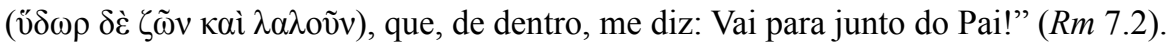

\section{Referências}

ANDERSON, Gary. The Garden of Eden and sexuality in early Judaism. In: EILBERGSCHWARTZ, H. People of the body: Jews and Judaism from an embodied perspective. Albany: State University of New York Press, 1992. p. 47-68.

BRIGHTON, Louis A. Revelation. Saint Louis: CPH, 1999.( Concordia Commentary).

CAPPS, E.; PAGE, T. E.; ROUSE, W. H. D. (Eds.). The Apostolic Fathers I. The Loeb Classical Library. London: William Heinemann; New York: G. P. Putnam's Sons, 1919.

CHARLES, R. H. A Critical and Exegetical Commentary on The Revelation of St. John. Edinburgh: T \& T Clark, 1920. (The International Critical Commentary, v. 2).

CHARLESWORTH, J. H. The Old Testament Pseudepigrapha and the New Testament: Prolegomena for the Study of Christian Origins. Cambridge: Cambridge University Press, 1985. 
CUVILLIER, Élian. La construction de la temporalité et de l'espace dans quelques textes de l'Apocalypse de Jean. Implications theologiques, anthropologiques et politiques. Conférence donnée dans le cadre du symposium du RRENAB («Narrativité et politique», 2-4 juin 2017, Université Laval à Québec). Disponível em: <https://www.academia.edu/35829016/LA_CONSTRUCTION_DE_LA_TEMPORALITE_ET_DE_LESPACE_DANS_QUELQUES_TEXTES_DE_LAPOCALYPSE_DE_JEAN._IMPLICATIONS_THEOLOGIQUES_ANTHROPOLOGIQUES_ET_POLITIQUES_1>. Acesso em: 14 jun. 2018.

ELLUL, Jacques. Apocalipse: Arquitetura em movimento. Trad. Maria Luísa de Albuquerque Silva. São Paulo: Paulinas, 1979.

FRIEDRICH, Nestor. Adapt or Resist? A Socio-Political Reading of Revelation 2.18-29, JSNT, v. 25, n. 2, p. 185-211, 2002.

FRIESEN, Steven. Poverty in Pauline Studies: Beyond the So-called New Consensus. JSNT, v. 26, n. 3, p. 323-361, 2004.

GREIMAS, Algirdas J. A Problem of Narrative Semiotics: Objects of Value. In: GREIMAS, Algirdas J. On Meaning: Selected Writings in Semiotic Theory. Minneapolis: University of Minnesota Press, 1987. p. 84-105.

GUNDRY, Robert. The New Jerusalem - People as Place, Not Place for People. Novum Testamentum, XXIX, 3, p. 254-264, 1987.

KOESTER, Craig R. Revelation - A New Translation with Introduction and Commentary (The Anchor Bible). New Haven; London: Yale University Press, 2014.

KRAYBILL, J. Nelson. Imperial Cult and Commerce in John's Apocalypse. Sheffield: Sheffield Academic Press, 1996.

LAZARIN, Cleide. A água da vida e o sentido da vida. 2013. Dissertação (Mestrado em Ciências da Religião) - Pontifícia Universidade Católica de Goiás, Goiânia, 2013.

MACASKILL, Grant. Paradise in the New Testament. In: BOCKMUEHL, M.; STROUMSA, G. G. Paradise in Antiquity. Cambridge: Cambridge University Press, 2010. p. 64-81.

MARTÍNEZ, Florentino García; TIGCHELAAR, Eibert J. C. (eds.). The Dead Sea Scrolls Study Edition. Leiden; New York; Köln: Brill, 1999. 2 v.

MOUNCE, Robert. The Book of Revelation. Grand Rapids: Eerdmans, 1977. (The New International Commentary on the New Testament).

PENNER, Ken. Realized or Future Salvation in the Hodayot. Journal of Biblical Studies, v. 2, p. 1-49, 2002.

RIOS, Cesar Motta. “Águas vivas” no Evangelho segundo João, na Bíblia Hebraica e nos manuscritos do Mar Morto: Entre Continuidades e Diferenças. Estudos Teológicos, v. 57, n. 1, p. 157-170, jan./jun. 2017. Disponível em: < http://periodicos.est.edu.br/index.php/estudos_teologicos/article/view/2927/pdf>. Acesso em: 14 jun. 2018.

STANLEY, John E. The New Creation as a People and City in Revelation 21:1-22:5: An Alternative to Despair. The Asbury Theological Journal, v. 60, n. 2, p. 25-38, 2005.

STUCKENBRUCK, Loren; MATHEWS, Mark. The Apocalypse of John, 1 Enoch, and the Question of Influence. In: FREY, Jörg; KELHOFFER, James; TÓTH, Franz. (Eds.) Die Johannesapokalypse: Kontexte - Konzepte - Rezeption. Tübingen: Mohr Siebeck, 2012.

SWETE, Henry Barclay. Commentary on Revelation. Grand Rapids: Kregel, 1977.

THE GREEK NEW TESTAMENT. Fourth Revised Edition. Edited by Barbara Aland et al. Stuttgart: Deutsche Bibelgesellschaft, 2000.

VANNI, Hugo. Apocalipse: uma assembleia litúrgica interpreta a história. São Paulo: Paulinas, 1984. 